\title{
Social isolation during puberty affects female sexual behavior in mice
}

\author{
Jasmina Kercmar ${ }^{1}$, Stuart A. Tobet ${ }^{2}$ and Gregor Majdic ${ }^{1,3}$ * \\ ' Veterinary Faculty, Center for Animal Genomics, University of Ljubljana, Ljubljana, Slovenia \\ ${ }^{2}$ Department of Biomedical Sciences, Colorado State University, Fort Collins, CO, USA \\ ${ }^{3}$ Institute of Physiology, Medical School, University of Maribor, Maribor, Slovenia
}

Edited by:

Regina M. Sullivan, Nathan Kline

Institute and NYU School of

Medicine, USA

Reviewed by:

Elaine M. Hull, Florida State

University, USA

Mouna Maroun, University of Haifa,

Israel

*Correspondence:

Gregor Majdic, Veterinary Faculty,

Center for Animal Genomics,

University of Ljubljana, Gerbiceva

60, SI-1000 Ljubljana, Slovenia

e-mail: gregor.majdic@vf.uni-lj.si
Exposure to stress during puberty can lead to long-term behavioral alterations in adult rodents coincident with sex steroid hormone-dependent brain remodeling and reorganization. Social isolation is a stress for social animals like mice, but little is known about the effects of such stress during adolescence on later reproductive behaviors. The present study examined sexual behavior of ovariectomized, estradiol and progesterone primed female mice that were individually housed from 25 days of age until testing at approximately 95 days, or individually housed from day 25 until day 60 (during puberty), followed by housing in social groups. Mice in these isolated groups were compared to females that were group housed throughout the experiment. Receptive sexual behaviors of females and behaviors of stimulus males were recorded. Females housed in social groups displayed greater levels of receptive behaviors in comparison to both socially isolated groups. Namely, social females had higher lordosis quotients (LQs) and more often displayed stronger lordosis postures in comparison to isolated females. No differences between female groups were observed in stimulus male sexual behavior suggesting that female "attractiveness" was not affected by their social isolation. Females housed in social groups had fewer cells containing immunoreactive estrogen receptor (ER) $\alpha$ in the anteroventral periventricular nucleus (AVPV) and in the ventromedial nucleus of the hypothalamus (VMH) than both isolated groups. These results suggest that isolation during adolescence affects female sexual behavior and re-socialization for 1 month in adulthood is insufficient to rescue lordosis behavior from the effects of social isolation during the pubertal period.

Keywords: mice, social isolation, female sexual behavior, estrogen receptor $\alpha$, puberty/adolescence

\section{INTRODUCTION}

Puberty is a period during which an individual attains sexual maturity following the re-activation of the hypothalamicpituitary-gonadal (HPG) axis and elevated secretion of gonadal steroid hormones (Sisk and Zehr, 2005; Schulz and Sisk, 2006). During puberty, the brain undergoes remodeling and reorganization which is partially influenced by gonadal steroid hormones (Schulz et al., 2009). There is growing evidence that exposure to stressors in adolescence can cause profound longlasting alterations in the brain and subsequently in behavior in adulthood, perhaps due to interactions between sex hormones and hypothalamic-pituitary-adrenal (HPA) function (McCormick and Mathews, 2007; McCormick et al., 2010; Blaustein and Ismail, 2013). In social mammals like mice and rats, isolation can be stressful (Dixon, 2004; Koolhaas, 2010). Postweaning social isolation behavioral studies have frequently been done in males, although some studies performed in both sexes suggest differences in the effects of social stress during adolescence, with males appearing to be more vulnerable (reviewed in Blanchard et al., 2001; Fone and Porkess, 2008).
Female sexual behavior is a complex set of behaviors that are necessary and sufficient to achieve fertilization of female ova by male sperm (Nelson, 2005). Two types of female sexual behaviors are often distinguished in rodents: receptive (reflexive postural changes at copulation - lordosis) and proceptive (attracting and initiating copulation) behaviors (Crusio et al., 2013). However, proceptive behaviors are more pronounced in rats than in mice and are difficult to evaluate in mice (Nelson, 2005). Female sexual behavior is mostly regulated by action of sex steroid hormones and neurons in many brain regions sensitive to the action of ovarian steroid hormones (mainly estradiol) are thought to be involved in the regulation of female sexual behavior including those in the preoptic area and ventromedial hypothalamic nuclei (Flanagan-Cato and McEwen, 1995; Rissman et al., 1999; Musatov et al., 2006). The estrogen receptor (ER) $\alpha$ present in neurons in these regions is essential for the effects of estradiol on the expression of sexual receptivity (Rissman et al., 1999). The medial amygdala (MeA) is also rich in estradiol receptors and is another region that may be involved in the regulation of female sexual behavior (DiBenedictis et al., 2012). 
For example, Fos expression was much higher in the MeA of mated than non-mated females (Flanagan-Cato and McEwen, 1995). ER $\alpha$ can be autoregulated with estradiol down-regulating the expression of ER $\alpha$ in many brain areas (e.g., Simerly and Young, 1991; DonCarlos et al., 1995; Gréco et al., 2001). Stress activates the HPA axis and this can suppress HPG axis activity. Stressed animals may therefore be exposed to lower levels of gonadal hormones (reviewed in Kalantaridou et al., 2004) and this could cause an increase in ER $\alpha$ expression and detection of immunoreactive $\mathrm{ER} \alpha$.

In female mice, some stressors such as LPS injections during the peripubertal period (around 42 days of age) caused reductions in the level of receptive behavior lordosis quotient (LQ). This effect was stronger if mice were stressed peripubertally than if they were stressed in adult life (Laroche et al., 2009a,b). However, not all stressors were equally effective in decreasing receptive behaviors. For example, restraint stress and food deprivation did not have strong effects on these behaviors (Laroche et al., 2009a). The current study reports on the influence of social isolation during pubertal period on sexual behavior in adult female mice, and whether social re-housing in adulthood could eliminate behavioral alterations provoked by social isolation during this vulnerable adolescent period. Sexual behavior was examined in female mice that were group housed, socially isolated (from 25 days of age onwards), or isolated only during the pubertal period (25-60 days of age) followed by group housing. The goal was to explore whether the social isolation during pubertal period might have long-lasting effects on sexual behavior in adult female mice and on the expression of ER $\alpha$ in brain regions important for the regulation of female sexual behavior.

\section{MATERIALS AND METHODS ANIMALS}

C57BL/6J mice were originally obtained from Harlan (Italy) and bred at the University of Ljubljana, Veterinary Faculty, in standard conditions with 12-12 light/dark cycle (lights on at 3 am and off at $3 \mathrm{pm}$ ) and food (phytoestrogen free diet; Harlan Teklad Diet 2016, Harlan, Milan, Italy) and water ad libitum. Mice were weaned at 21 days of age and at 25 days of age females were divided into three groups:

1. group-housed with at least 3 mice per cage (Social),

2. socially isolated with 1 mouse per cage (Isolated),

3. socially isolated and regrouped at 60 days of age (Isol/Social).

Social females (Social, $n=8$ ) were housed in larger $15 \mathrm{~cm}$ high cages with floor area of $37.5 \times 22 \mathrm{~cm}$, socially isolated females (Isolated, $n=8$ ) in smaller $14 \mathrm{~cm}$ high cages with $35 \times$ $15 \mathrm{~cm}$ floor area, and the transiently isolated females (Isol/Social, $n=8$ ) first in smaller cages and after regrouping in larger cages. Sexually experienced stimulus males of the same strain $(n=9)$ were individually housed in $13 \mathrm{~cm}$ high cages with $28.5 \times 10.5 \mathrm{~cm}$ floor area that had been previously used for mating (at least 3 successful matings with weaned litters). The C57BL/6J mice were chosen because this is a commonly used reference strain for behavioral phenotyping studies with high rates of copulatory behaviors displayed (reviewed in Crawley et al., 1997).
All animal experiments were approved by the Veterinary Administration of the Republic of Slovenia and were done according to ethical principles, EU directive, and NIH guidelines.

\section{SURGERY AND HORMONAL TREATMENTS}

All female mice were ovariectomized bilaterally at 60 days of age (after puberty) to eliminate endogenous gonadal steroids. Mice were anesthetized with the mixture of ketamine (Vetoquinol Biowet, Gorzowie, Poland; $100 \mu \mathrm{g} / \mathrm{g} \mathrm{BW}$ ), acepromazine (Fort Dodge Animal Health, Fort Dodge, IA, USA; $2 \mu \mathrm{g} / \mathrm{g}$ BW) and xylazine (Chanelle Pharmaceuticals Ltd., Loughrea, Ireland; $10 \mu \mathrm{g} / \mathrm{g}$ BW) and gonads were excised through small incisions. The incisions were stitched (absorbable sutures; Safil, Braun, Aesculap, Tuttlingen, Germany) and mice received two injections of butorfanol (Turbogesic, Fort Dodge Animal Health, Fort Dodge, IA, USA; $2 \mu \mathrm{g} / \mathrm{g}$ BW) after surgery to alleviate potential pain. To regulate circulating estradiol levels in adulthood at approximately 80 days of age mice received subcutaneous implants containing estradiol benzoate. Silastic implants $(1.02 \mathrm{~mm}$ inner diameter, $2.16 \mathrm{~mm}$ outer diameter) were filled $5 \mathrm{~mm}$ in length with crystalline $\beta$-estradiol 3-benzoate (EB; Sigma), diluted 1:1 with cholesterol (Sigma) (Wersinger et al., 1999) and closed on both ends by medical silastic adhesive (Dow Corning). Implants were inserted subcutaneously in the midscapular region under anesthesia (mixture of ketamine (Vetoquinol Biowet, Gorzowie, Poland; $100 \mu \mathrm{g} / \mathrm{g}$ BW), acepromazine (Fort Dodge Animal Health, Fort Dodge, IA, USA; $2 \mu \mathrm{g} / \mathrm{g}$ BW) and xylazine (Chanelle Pharmaceuticals Ltd., Loughrea, Ireland; $10 \mu \mathrm{g} / \mathrm{g}$ BW). These implants yield plasma estradiol levels close to the physiological range normally observed during estrus (Wersinger et al., 1999). Behavior tests were performed at least 10 days after implantation. Approximately 4-8 h before each test the females were injected subcutaneously with $0.8 \mathrm{mg}$ of progesterone (P; Sigma) dissolved in corn oil (Sigma). All mice were initially tested for sexual behavior between 90 and 100 days of age, and were sacrificed by transcardial perfusion fixation with $4 \%$ paraformaldehyde 4 days after the last test, around 125 days of age, and the brains were dissected and stored in $0.1 \mathrm{M} \mathrm{PB}$ at $4^{\circ} \mathrm{C}$ until further processing for immunohistochemistry.

\section{FEMALE SEXUAL BEHAVIOR TEST}

Female sexual behavior tests were performed in clear glass aquaria (17 cm high with $41.5 \times 26 \mathrm{~cm}$ floor area) with a mirror positioned under the testing arena to obtain better views of facets of sexual behaviors (Wersinger et al., 1997). Females were tested during the first $2-4 \mathrm{~h}$ of the dark period of the circadian cycle, under dim red light illumination, and the test sessions were videotaped for subsequent scoring. Each female was tested 6 times, every $4-5$ days to mimic the normal physiological estrus cycle. The first trial served for animals to gain sexual experience prior to testing, the next five trials were scored. The stimulus males were placed into the aquarium at least $4 \mathrm{~h}$ prior behavior testing with at least 3 day old bedding and food and water ad libitum to acclimate to the novel environment. Food and water were removed during the behavior tests.

Hormonally-primed females were placed in the middle of aquaria with a stimulus male for 20 min (Park, 2011), or until 
the female received an ejaculation. The following behaviors were recorded: lordosis posture, total number and latency of attempted mounts, successful mounts, pelvic thrusts and intromissions, and the latency of ejaculation. Behaviors were recorded by "stopwatch" software (Center for Behavioral Neuroscience, Atlanta, GA) and were observed by the same investigator (Jasmina Kercmar) who was blinded to the group assignment at the time of testing.

If the stimulus male did not try to mount the female, after 5 min of testing the tested female was moved to another aquaria with a new, previously habituated stimulus male. Ejaculating males were not used again for the remainder of the trial day. Mounts were counted when the female had all four limbs on the floor. Female lordosis posture as an index of sexual receptivity was scored from 0 (no receptive behavior with no lordosis reflex) to 5 (completely receptiveness with strongest lordosis reflex as described previously (Bakker et al., 2002). Lordosis was defined using the following stipulations: all four paws are grounded, hind region is elevated off the floor of the test chamber, and the back is slightly arched (Takasugi et al., 1983; Kudwa et al., 2007). A LQ was calculated by the following formula: number of mounts during which the female stood still (lordosis 4 and 5)/total number of attempted and successful mounts $\times 100$.

\section{ER $\alpha$ IMMUNOHISTOCHEMISTRY}

Brains were embedded in 5\% agarose (Sigma) and sectioned at $50 \mu \mathrm{m}$ in cold $0.05 \mathrm{M}$ PBS using a vibrating microtome (Integraslice $7550 \mathrm{MM}$, Campden Instruments, UK). Sections were incubated in $0.1 \mathrm{M}$ glycine (Sigma) in cold $0.05 \mathrm{M}$ PBS for $30 \mathrm{~min}$ followed by incubation in $0.5 \%$ sodium borohydride (Sigma) for $15 \mathrm{~min}$ at $4^{\circ} \mathrm{C}$. Glycine and sodium borohydride were washed out with $15 \mathrm{~min}$ and $20 \mathrm{~min}$ washes (every $5 \mathrm{~min}$ ) in cold $0.05 \mathrm{M}$ PBS. Sections were blocked in 5\% normal goat serum (Jackson Immunoresearch, West Grove, PA, USA) containing $0.5 \%$ Triton X-100 (Sigma) and $1 \% \mathrm{H}_{2} \mathrm{O}_{2}$ (Merck, Darmstadt, Germany) for $30 \mathrm{~min}$ at $4^{\circ} \mathrm{C}$. Rabbit primary antiserum against $\mathrm{ER} \alpha$ (1:5000, Cat.\#06-935, Upstate, Lake Placid, NY, USA) were diluted in $0.05 \mathrm{M}$ PBS containing $1 \%$ bovine serum albumin (Sigma) and $0.5 \%$ Triton X-100. Sections were incubated with primary antibodies over $2-3$ nights at $4^{\circ} \mathrm{C}$ with shaking. Sections were after then washed in $0.05 \mathrm{M}$ PBS containing $1 \%$ normal goat serum and $0.02 \%$ Triton $\mathrm{X}-100$ four times for $15 \mathrm{~min}$ at room temperature. Biotinylated secondary antibodies (Jackson Immunoresearch) against primary rabbit antiserum were diluted $1: 500$ in $0.05 \mathrm{M}$ PBS containing $1 \%$ normal goat serum and $0.5 \%$ Triton X-100. Sections were incubated with biotinylated secondary antibodies for $2 \mathrm{~h}$, followed by 4 washes for $15 \mathrm{~min}$ in $0.05 \mathrm{M}$ PBS buffer containing $0.02 \%$ Triton X-100. Streptavidin-HRP complex (Jackson ImmunoResearch) was diluted 1:2500 in 0.05 M PBS solution containing $0.5 \%$ Triton X-100. Sections were incubated with StreptavidinHRP for $1 \mathrm{~h}$ at room temperature and then washed in Trisbuffered saline (0.05 M Tris- $\mathrm{HCl} / 0.9 \% \mathrm{NaCl}$; pH 7.5; Sigma) for $1 \mathrm{~h}$ (four times for $15 \mathrm{~min}$ ) at room temperature. Antigenantibody complexes were visualized as a black reaction product by incubating sections in $0.025 \% 3,3^{\prime}$-diaminobenzidine $/ 0.2 \%$ ammonium nickel (II) sulfate substrate (Sigma) in Tris-buffered saline containing $0.02 \% \mathrm{H}_{2} \mathrm{O}_{2}$ for $5 \mathrm{~min}$ at room temperature. Sections were finally washed in Tris-buffered saline three times every $10 \mathrm{~min}$. After mounting, sections were dried and coverslipped using hydrophobic medium (Pertex; Burgdorf, Germany).

\section{DATA COLLECTION AND ER $\alpha$ QUANTIFICATION}

Digital images of brain regions of interest were obtained using a Nikon Eclipse 80i microscope with Nikon DS-Fil camera. Images were enhanced for contrast using Adobe Photoshop software (Version 8.0). The number of immunoreactive cells or total area that was immunoreactive for $\mathrm{ER} \alpha$ was analyzed in coronal sections containing the anteroventral periventricular region (AVPV) between 0.26 and $0.14 \mathrm{~mm}$ rostral from Bregma, the ventromedial hypothalamic region (VMH) $1.70 \mathrm{~mm}$ caudal from Bregma, and MeA $1.22 \mathrm{~mm}$ caudal from Bregma according to stereotaxic coordinates (Franklin and Paxinos, 2008). All digital images were taken under 100x magnification. The base of the brain was considered as a reference boundary with the third ventricle in the center of the images for AVPV, the third ventricle and the base of the brain as reference boundaries for $\mathrm{VMH}$, and the junction of the optic nerve and cortex-amygdala transition as reference boundary with this junction in the middle of the lateral sides of the images for MeA. Due to the possibility of asymmetry in antigen detection in $\mathrm{VMH}$ and MeA between the left and right sides of the brain, the side (unilateral) with more immunopositive cells was always chosen for analysis. Immunoreactivity in AVPV was assessed on both sides (bilateral) of the third ventricle, extending approximately $640 \mu \mathrm{m}$ laterally from the third ventricle and $960 \mu \mathrm{m}$ dorsally from the base of the brain. Due to the large number of overlapping immunopositive $\mathrm{ER} \alpha$ cells in AVPV, the immunoreactive area was quantified using custom software (Surfkvad; made by Dr. Marko Kreft, Institute of pathophysiology, Faculty of Medicine, Ljubljana) that divides an image into $6 \times 8$ squares (measuring $160 \times 160 \mu \mathrm{m}$ each under 100x magnification) and calculates a percentage of dark area for each square (Büdefeld et al., 2008). To standardize the collection of immunoreactive area data, all images were taken under the same illumination and converted to grayscale. Grayscale images were subjected to threshold conversion to selectively identify immunoreactive elements using Photoshop software. Black and white images were then analyzed with Surfkvad. The number of immunopositive cells in the VMH and MeA was counted with the help of Image J software (NIH, Bethesda, MD). The grayscale images were divided into a grid of $6 \times 8$ squares for $\mathrm{VMH}$ (measuring $160 \times 160 \mu \mathrm{m}$ each), and a grid of $8 \times 10$ squares for MeA (measuring $120 \times 120 \mu \mathrm{m}$ each ). Only the grid delimiting the $\mathrm{VMH}$ region $(4 \times 4$ squares; extending approximately from $480 \mu \mathrm{m}$ to $1120 \mu \mathrm{m}$ laterally from the third ventricle and $640 \mu \mathrm{m}$ dorsally from the base of the brain), and the grid delimiting the MeA region $(3 \times 3$ squares; extending approximately from $120 \mu \mathrm{m}$ to $480 \mu \mathrm{m}$ laterally, $120 \mu \mathrm{m}$ ventrally and $240 \mu \mathrm{m}$ dorsally from the lateral boundary) were analyzed (Figures 2B,C).

\section{STATISTICAL ANALYSES}

All data were statistical analyzed using NCSS software (NCSS statistical software, Kaysville, UT, USA). To test differences between 


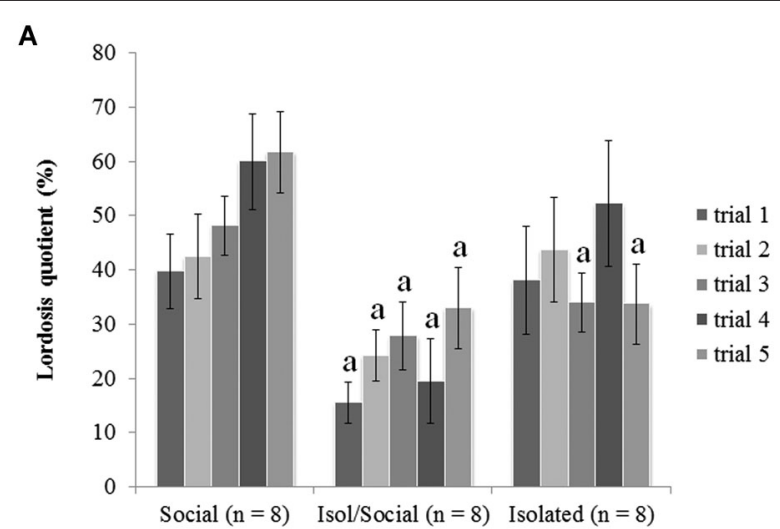

B

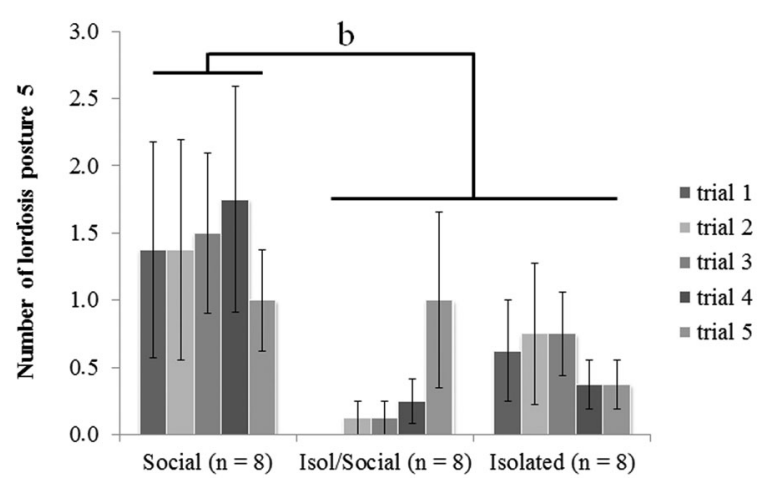

FIGURE 1 | Mice that were socially isolated during puberty showed impaired receptive female sexual behavior. (A) LQ $\left({ }^{a} p<0.01\right)$,

(B) number of displayed lordosis posture scored with $5\left({ }^{b} p<0.05\right)$. Data are reported as mean \pm SEM; ${ }^{a, b}$ Significant difference between females housed in social groups (Social) and other two isolated groups (Isol/Social, Isolated).

groups in sexual behavior tests, repeated measures ANOVA was performed with housing condition as independent variable, and trial as a repeated measure (within) factor, followed by post hoc Fisher LSD tests. Eight mice in each group were tested for female sexual behaviors (Social, $n=8$; Isolated, $n=8$; Isol/Social, $n=8$ ). Differences between groups in the number or area of immunoreactive ER $\alpha$ were analyzed by ANOVA followed by Fisher LSD post hoc (for VMH and amygdala) and by repeated measures ANOVA followed by Fischer LSD post hoc test (for AVPV). At least 4 brains in each group were analyzed and differences were considered statistically significant at $p<0.05$.

\section{RESULTS}

\section{SEXUAL BEHAVIOR OF FEMALE MICE}

Social isolation during adolescence reduced female sexual behaviors, and re-socialization in adulthood was insufficient to rescue receptive lordosis behavior from the effects of social isolation during the pubertal period. ANOVA revealed a significant overall effect of housing condition $\left[F_{(3,24)}=7.57, p<0.01\right]$ on the LQ between all three groups (Figure 1A). The post hoc tests indicated that mice housed in social groups (Social) had higher LQs in comparison with mice isolated for the limited period (Isol/Social) in all five trials while mice isolated throughout the experiment differ from the socially housed group selectively in trials 3 and 5.

ANOVA also showed significant effect of housing condition on the number of displayed lordosis reflexes scored 5 (the highest receptiveness with strongest lordosis reflex) $\left[F_{(3,24)}=5.32\right.$, $p<0.05$ ] (Figure 1B). Post hoc analysis showed that socially housed mice (Social) displayed lordosis reflexes scores of 5 more often than did other two groups of female mice (Isol/Social, Isolated). There were no statistically significant differences between permanently isolated mice and mice isolated only during the pubertal period, suggesting that 1 month re-socialization could not rescue from the effects of social isolation during puberty.

\section{SEXUAL BEHAVIOR OF STIMULUS MALE MICE}

No differences between female groups (Social, Isol/Social and Isolated) were observed in stimulus male sexual behavior, suggesting that female "attractiveness" was not affected by social isolation.

Repeated measures ANOVA did not show any significant effect of housing conditions (Social, Isol/Social and Isolated; means \pm SEMs of all five trials) in the total number of mounts $(19.1 \pm 2.2,19.9 \pm 1.9$ and $13.7 \pm 1.4)$, thrusts $(326.3 \pm 33.1$, $299.0 \pm 30.3$ and $268.3 \pm 26.3)$, or intromissions $(16.7 \pm 2.0$, $15.5 \pm 1.7$ and $11.8 \pm 1.3$ ) nor in the latencies to mount $(54.8 \pm 9.1,56.4 \pm 7.7$ and $69.9 \pm 12.0)$, intromit $(82.8 \pm 14.4$, $112.6 \pm 17.4$ and $109.7 \pm 17.2)$, or ejaculate $(793.9 \pm 65.9$, $923.1 \pm 60.2$ and $767.5 \pm 68.9)$.

\section{EXPRESSION OF ER $\alpha$ IN AVPV, VMH AND MeA}

Statistically significant differences in ER $\alpha$ immunoreactivity were found in the AVPV, VMH, but not in the MeA (Figures 2, 3). Socially housed mice had less ER $\alpha$ immunoreactive area than isolated mice of both groups. Repeated measures ANOVA with columns as the within factor showed a significant effect of housing condition in the total immunoreactivity for $\mathrm{ER} \alpha$ in cells in the $\operatorname{AVPV}\left[F_{(3,14)}=6.72, p<0.01\right]$ (Figures 2A, 3A). ANOVA revealed a significant effect of housing condition in the number of $\mathrm{ER} \alpha$ immunoreactive cells in the VMH $\left[F_{(3,16)}=3.93, p<0.05\right]$ (Figures 2B, 3B), but not in the MeA (Figures 2C, 3C). Post hoc analysis revealed that socially housed mice (Social) had less ER $\alpha$ immunoreactive area in the AVPV and less ER $\alpha$ immunoreactive cells in the VMH than the other two housing groups (Isol/Social, Isolated; Figures 3A,B). Mice isolated throughout the experiment or only during puberty had more immunoreactive area or more cells in the AVPV and VMH, respectively, than socially housed mice, and there was no statistical difference in total immunoreactivity or number of cells in both AVPV and VMH between permanently isolated mice and mice isolated for transient time only (Figures 3A,B).

\section{DISCUSSION}

Beside the pre- and early postnatal period, the pubertal period is important for the appropriate development of specific behaviors displayed in adulthood (Sisk and Zehr, 2005). Early life stress can have profound influences on brain development and subsequently on behavior later in life (reviewed in McCormick et al., 2010). Particular stressors during the pubertal period in female mice (Laroche et al., 2009a,b; Ismail et al., 2011) may 

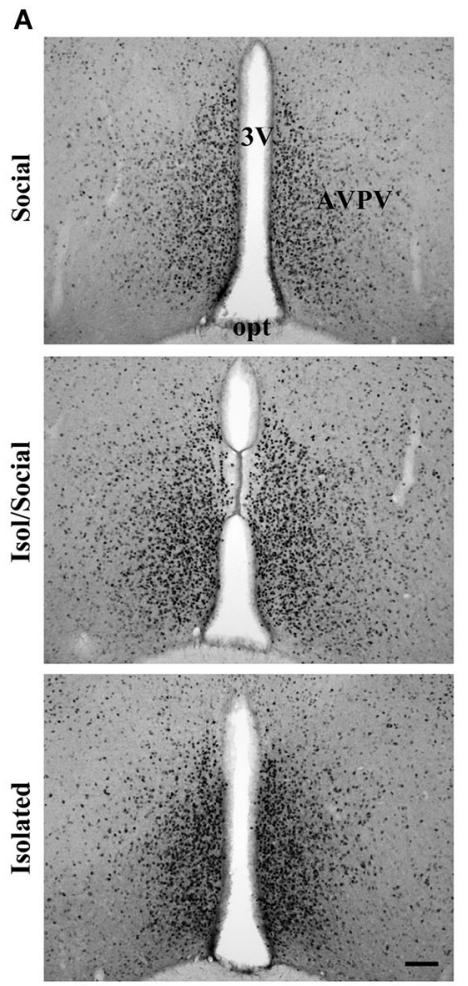

B
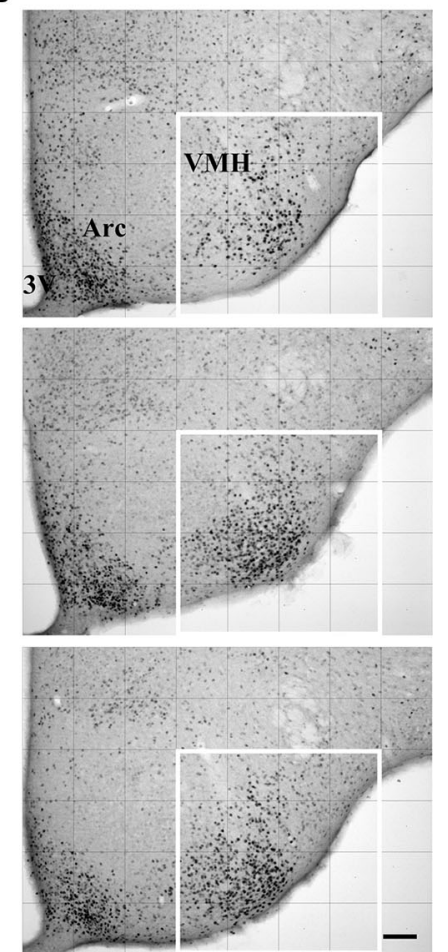

C
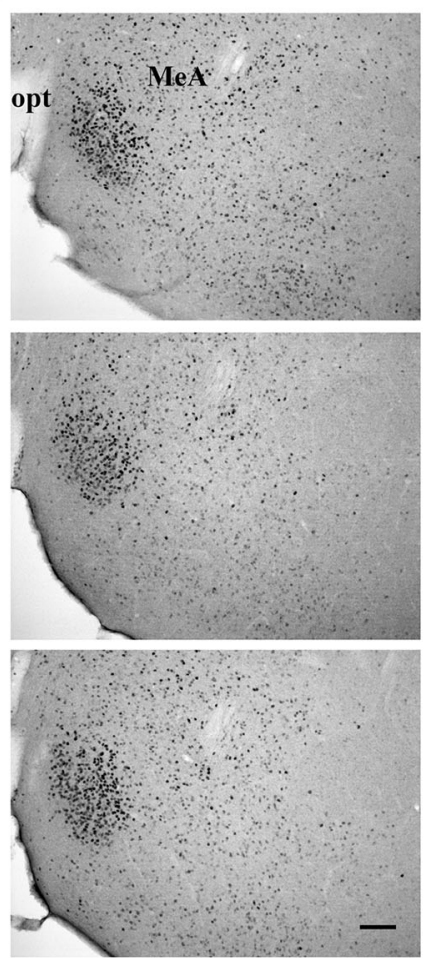

FIGURE 2 | Digital images showing ER $\alpha$ immunoreactive cells.

(A) In the anteroventral paraventricular nucleus (AVPV), (B) ventromedial nucleus of the hypothalamus (VMH) and (C) in the medial amygdala (MeA) in socially housed mice (Social), isolated for transient time
(Isol/Social) and in isolated throughout the experiment (Isolated). In the $\mathrm{VMH}$ images, the white square denotes the area analyzed. Bar $=100 \mu \mathrm{m}$. 3V-third ventricle, opt-optic nerve, Arc-arcuate nucleus. cause enduring changes in behavioral responsiveness of the brain to estradiol and progesterone. The current study provides new information about the effects of a different source of stress, post-weaning social isolation, on female sexual behavior. Sexual behavior was examined in female mice that were individually or group housed from 25 days of age throughout the experiment, or individually housed from day 25 until day 60 (during puberty), followed by housing in social groups. The results of the current study suggest the importance of the social environment during puberty for the display of sexual behaviors in adult female mice.

In the current study socially housed female mice displayed stronger lordosis behavior in comparison to mice that were socially isolated during puberty (Isol/Social or Isolated). There were no significant differences between mice that were isolated during puberty vs. re-socialized afterward. Therefore, 1 month re-socialization was insufficient to rescue the behavior from the deleterious effects of social isolation during puberty. This is consistent with previous reports about sexual behavior in female mice that were exposed to different stressors during the peripubertal adolescent period (Laroche et al., 2009a,b; Ismail et al., 2011). In the current study there was a significant overall effect of housing on LQ. However, post hoc tests revealed significant differences between social and social/isol groups in all five trials while the difference in LQ was significantly different between social and isol groups more selectively in trials 3 and 5. This is intriguing, as it suggests a potentially stronger effect of temporary isolation than permanent isolation. Perhaps this could be explained by the possibility that re-socialization after isolation during puberty might present additional stress for female mice, while persistent isolation possibly force mice to adapt to the isolation and in longer period of isolation somehow compensate some of the effects of isolation stress. The observation that isolation stress selectively during puberty had a stronger effect on LQ than isolation throughout the experiment is partially in agreement with the previous study by Laroche and coworkers that reported mice exposed to stress (shipping or LPS injection) at 6 weeks of age (peripubertally) show lower levels of sexual receptivity than mice exposed to the same stressors at 12 weeks of age (in adulthood) or control mice (Laroche et al., 2009a,b). Thus, the pubertal period might be an especially vulnerable period for stress to cause alterations in the circuitry regulating female sex behavior. In contrast, sexual behavior of socially housed or isolated female rats after weaning did not differ (Duffy and Hendricks, 1973), suggesting that female mice might be more vulnerable to social isolation stress during puberty than female rats. As expected, there were too few proceptive behaviors (sniffing or following the male) seen in any female mice to analyze impact. Interestingly, the sexual behaviors of stimulus males (mounts, thrusts, intromissions and ejaculation) were not altered by the 


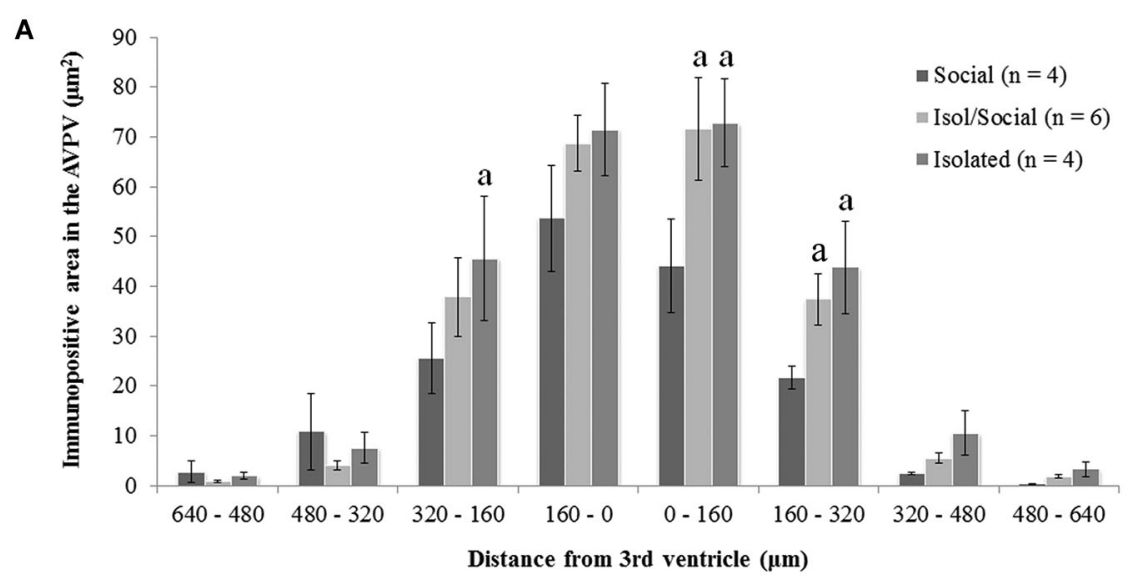

B

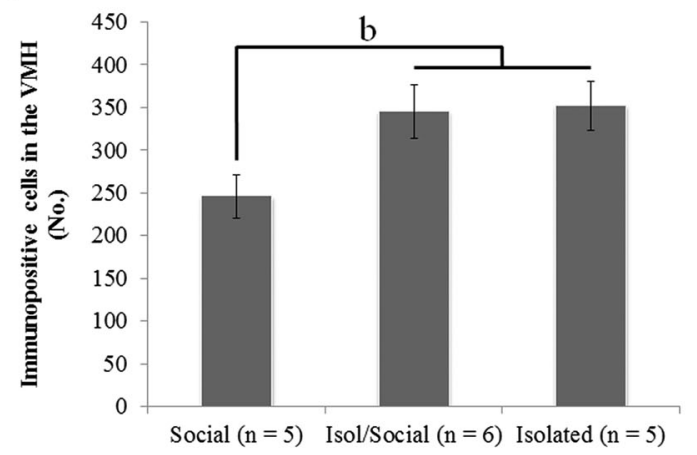

FIGURE 3 | Social isolation during puberty increases ER $\alpha$ immunoreactivity in the anteroventral paraventricular nucleus (AVPV) and in the ventromedial nucleus of the hypothalamus (VMH), but not in the medial amygdala (MeA). (A) Area of representing immunopositive ER $\alpha$ cells in the AVPV on both sides of the third ventricle $\left({ }^{a} p<0.01\right)$, (B) total
C

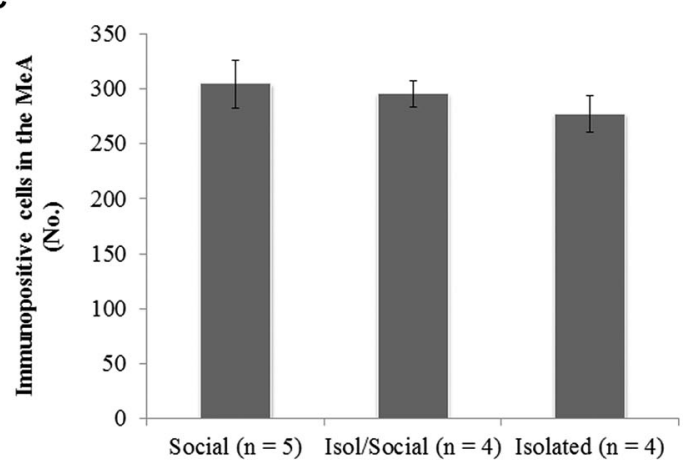

number of immunopositive $\mathrm{ER} \alpha$ cells in the $\mathrm{VMH}\left({ }^{b} p<0.05\right)$, (C) total number of immunopositive $E R \alpha$ cells in the MeA. Data are reported as mean \pm SEM; ${ }^{a}$ Significantly different from females housed in social groups (Social). ${ }^{b}$ Significant difference between females housed in social groups (Social) and other two isolated groups (Isol/Social, Isolated). different housing regimes of the test females, suggesting that female "attractiveness" was not affected by social isolation during puberty.

Estradiol effects in the brain are mediated via interactions with ERs and for the regulation of female sexual behavior by estradiol, $\mathrm{ER} \alpha$ is essential (Ogawa et al., 1998; Rissman et al., 1999). MPOA, MeA, and VMH and other sites are rich in ERs that likely contribute to sexual behaviors (Flanagan-Cato and McEwen, 1995; Rissman et al., 1999; DiBenedictis et al., 2012). In the current study, social isolation (permanent or for a specifically limited period) increased the area of $\mathrm{ER} \alpha$ immunoreactivity in the AVPV and the number of ER $\alpha$ immunopositive cells in the VMH in comparison to socially housed mice. This contrasts with previous studies in mice (Ismail et al., 2011) and prairie voles (Ruscio et al., 2009), where females stressed during puberty had reduced numbers of ER $\alpha$ immunopositive cells in different brain areas (MPOA, BNST, VMH and arcuate nucleus) involved in the regulation of female sexual behavior in comparison to control animals. One report (Ismail et al., 2011) showed reduced levels of ER $\alpha$ in the MPOA, VMH and arcuate nucleus of adult mice (at 16 weeks of age), but not in the AVPV, after exposure to shipping stress during the pubertal period at 6 weeks of age. Another report (Ruscio et al., 2009) showed no differences in immunoreactive $\mathrm{ER} \alpha$ in the MeA and $\mathrm{VMH}$, but reduced expression in MPOA and BNST, between isolated and pair housed (different sex pairs) prairie voles. These differences among studies may be due to the use of different stressors, the timing of stress, and species or strain differences. All of these factors have been shown to cause differences in stress effects (reviewed in McCormick et al., 2010). Estradiol has been shown to auto-regulate its receptor expression with increased levels of estradiol having suppressive effects on ER $\alpha$ mRNA or protein (DonCarlos et al., 1995; Gréco et al., 2001). In the present study, all mice were exposed to estradiol prior to sacrifice and therefore the differences between groups are presumably due to differences in housing/exposure to social stress. The difference between our study and study by Ismail et al. (2011) which reported reduction of $\mathrm{ER} \alpha$ cell numbers in the $\mathrm{VMH}$ and no differences in AVPV could be explained by the duration of stress. Namely, in the current study, the stress was prolonged whereas in the prior study in mice (Ismail et al., 2011) the duration of stress was limited and short. Perhaps reduced 
expression of $\mathrm{ER} \alpha$ in certain brain areas presents a rebound effect following short stress and consequent suppression of HPG axis, followed perhaps by a compensatory period with increased estradiol levels. By contrast, prolonged stress could more permanently affect/reduce estradiol levels, causing an increase in receptor expression. Future studies should consider determining the time course of changes in ER $\alpha$ in the relevant brain areas and possible mediating factors.

As noted in the Introduction section, MeA is also thought to be involved in female sexual behavior, since mating increases c-Fos expression in this brain region (Flanagan-Cato and McEwen, 1995; Sah et al., 2003; DiBenedictis et al., 2012). However, another study in female rats suggested that impairment of sexual behavior is not due to $\mathrm{ER} \alpha$ knockdown in MeA (Spiteri et al., 2010a), indicating that female sexual behavior is not modulated by the $\mathrm{ER} \alpha$ in $\mathrm{MeA}$ in rats. As for many characteristics, it is difficult to know whether this is true for rats and mice (Bonthuis et al., 2010). Indeed, in the present study there was not a significant alteration in the number of ER $\alpha$ immunopositive cells in the MeA regardless of different housing regimes during puberty.

The amygdala is a major brain region mediating emotional and hormonal responses to stress (mainly the basolateral complex of amygdaloid nuclei and central nucleus of the centromedial complex) (reviewed in Sah et al., 2003). Regardless of the lack of influence of social isolation on immunoreactive $\mathrm{ER} \alpha$, alterations of lordosis behavior in socially isolated mice in the current study could be due to increased general anxiety or impaired social behaviors. Anxiety-like behaviors were not directly assessed. In the absence of proceptive behaviors or group differences in attractiveness to stimulus males, impaired lordosis behavioris perhaps less likely due to impaired social interactions. In agreement, a study in socially isolated female rats during puberty showed no differences in social interactions in comparison to socially grouped rats (Lukkes et al., 2012). Another study in mice found no differences in aggressive behavior in female mice of different housing conditions (Ouchi et al., 2013). Other studies of housing isolation stress after weaning in female C57BL/6J mice reported no effect on anxiety-like behavior in comparison to socially housed mice ( $\sim 4$ weeks of isolation (Pietropaolo et al., 2008) or $\sim 8$ weeks of isolation (Kulesskaya et al., 2011)). Interestingly, one study in socially housed female rats suggested that anxietylike behavior might be modulated by ER $\alpha$ in the MeA based on reductions of anxiety-like behaviors after silencing $\mathrm{ER} \alpha$ in the MeA (Spiteri et al., 2010b). The lack of differences in MeA ER $\alpha$ immunoreactivity in the current study might be taken to suggest that all three groups of females in the current study were in similar anxiety-like states.

In conclusion, the results of the current study suggest that social isolation stress during puberty/adolescence can have a profound effect on female sexual behavior and on the detection of immunoreactive $\mathrm{ER} \alpha$ in brain regions important for behavior regulation in adult female mice without impacting female attractiveness to stimulus males. Re-socialization for 1 month in adulthood could not reverse the effects of social isolation during the pubertal period. These results highlight the importance of social environment during puberty on the development of sexual receptivity in female mice and this should be taken into account when planning or interpreting results of such behavior assessment studies.

\section{ACKNOWLEDGMENTS}

This study was supported by ARRS grant P4-0053 (Gregor Majdic) and NIH grant MH61376 (Stuart A. Tobet and Gregor Majdic). We are thankful to Nina Sterman for animal husbandry and technical assistance.

\section{REFERENCES}

Bakker, J., Honda, S., Harada, N., and Balthazart, J. (2002). The aromatase knockout mouse provides new evidence that estradiol is required during development in the female for the expression of sociosexual behaviors in adulthood. $J$. Neurosci. 22, 9104-9112.

Blanchard, R. J., McKittrick, C. R., and Blanchard, D. C. (2001). Animal models of social stress: effects on behavior and brain neurochemical systems. Physiol. Behav. 73, 261-271. doi: 10.1016/s0031-9384(01)00449-8

Blaustein, J. D., and Ismail, N. (2013). Enduring influence of pubertal stressors on behavioral response to hormones in female mice. Horm. Behav. 64, 390-398. doi: 10.1016/j.yhbeh.2013.01.015

Bonthuis, P. J., Cox, K. H., Searcy, B. T., Kumar, P., Tobet, S., and Rissman, E. F. (2010). Of mice and rats: key species variations in the sexual differentiation of brain and behavior. Front. Neuroendocrinol. 31, 341-358. doi: 10.1016/j.yfrne. 2010.05.001

Büdefeld, T., Grgurevic, N., Tobet, S. A., and Majdic, G. (2008). Sex differences in brain developing in the presence or absence of gonads. Dev. Neurobiol. 68, 981995. doi: 10.1002/dneu.20638

Crawley, J. N., Belknap, J. K., Collins, A., Crabbe, J. C., Frankel, W., Henderson, N., et al. (1997). Behavioral phenotypes of inbred mouse strains: implications and recommendations for molecular studies. Psychopharmacology (Berl) 132, 107124. doi: 10.1007/s002130050327

Crusio, W. E., Sluyter, F., Gerlai, R. T., and Pietropaolo, S. (2013). Behavioral Genetics of the Mouse: Genetics of Behavioral Phenotypes. Cambridge Handbooks in Behavioral Genetics. New York: Cambridge University Press.

DiBenedictis, B. T., Ingraham, K. L., Baum, M. J., and Cherry, J. A. (2012). Disruption of urinary odor preference and lordosis behavior in female mice given lesions of the medial amygdala. Physiol. Behav. 105, 554-559. doi: 10. 1016/j.physbeh.2011.09.014

Dixon, A. K. (2004). “The social behaviour of mice and its sensory control," in The Laboratory Mouse, eds H. J. Hedrich and G. Bullock (London, San Diego: Elsevier Academic press), 287-300.

DonCarlos, L. L., Malik, K., and Morrell, J. I. (1995). Region-specific effects of ovarian hormones on estrogen receptor immunoreactivity. Neuroreport 6, 20542058. doi: 10.1097/00001756-199510010-00024

Duffy, J. A., and Hendricks, S. E. (1973). Influences of social isolation during development on sexual behavior of the rat. Anim. Learn. Behav. 1, 223-227. doi: 10.3758/bf03199079

Flanagan-Cato, L. M., and McEwen, B. S. (1995). Pattern of Fos and Jun expression in the female rat forebrain after sexual behavior. Brain Res. 673, 53-60. doi: 10. 1016/0006-8993(94)01395-x

Fone, K. C., and Porkess, M. V. (2008). Behavioural and neurochemical effects of post-weaning social isolation in rodents-relevance to developmental neuropsychiatric disorders. Neurosci. Biobehav. Rev. 32, 1087-1102. doi: 10.1016/j. neubiorev.2008.03.003

Franklin, K. B. J., and Paxinos, G. (2008). The Mouse Brain in Stereotaxic Coordinates. Amsterdam, Boston, Heidelberg, London, New York, Oxford, Paris, San Diego, San Francisco, Singapore, Sydney, Tokyo: Academic Press.

Gréco, B., Allegretto, E. A., Tetel, M. J., and Blaustein, J. D. (2001). Coexpression of ER beta with ER alpha and progestin receptor proteins in the female rat forebrain: effects of estradiol treatment. Endocrinology 142, 5172-5181. doi: 10. 1210/en.142.12.5172

Ismail, N., Garas, P., and Blaustein, J. D. (2011). Long-term effects of pubertal stressors on female sexual receptivity and estrogen receptor-alpha expression in CD-1 female mice. Horm. Behav. 59, 565-571. doi: 10.1016/j.yhbeh.2011.02.010

Kalantaridou, S. N., Makrigiannakis, A., Zoumakis, E., and Chrousos, G. P. (2004). Stress and the female reproductive system. J. Reprod. Immunol. 62, 61-68. doi: 10.1016/s0165-0378(04)00036-1 
Koolhaas, J. M. (2010). "The laboratory rat," in The UFAW Handbook on the Care and Management of Laboratory and Other Research Animals, eds R. Hubrecht and J. Kirkwood, 8th Edn. (Wheathampstead: Universities federation for animal welfare), 311-327.

Kudwa, A. E., Boon, W. C., Simpson, E. R., Handa, R. J., and Rissman, E. F. (2007). Dietary phytoestrogens dampen female sexual behavior in mice with a disrupted aromatase enzyme gene. Behav. Neurosci. 121, 356-361. doi: 10.1037/0735-7044. 121.2.356

Kulesskaya, N., Rauvala, H., and Voikar, V. (2011). Evaluation of social and physical enrichment in modulation of behavioural phenotype in $\mathrm{C} 57 \mathrm{BL} / 6 \mathrm{~J}$ female mice. PLoS One 6:e24755. doi: 10.1371/journal.pone.0024755

Laroche, J., Gasbarro, L., Herman, J. P., and Blaustein, J. D. (2009a). Enduring influences of peripubertal/adolescent stressors on behavioral response to estradiol and progesterone in adult female mice. Endocrinology 150, 3717-3725. doi: 10. 1210/en.2009-0099

Laroche, J., Gasbarro, L., Herman, J. P., and Blaustein, J. D. (2009b). Reduced behavioral response to gonadal hormones in mice shipped during the peripubertal/adolescent period. Endocrinology 150, 2351-2358. doi: 10.1210/en.20081595

Lukkes, J. L., Engelman, G. H., Zelin, N. S., Hale, M. W., and Lowry, C. A. (2012). Post-weaning social isolation of female rats, anxiety-related behavior and serotonergic systems. Brain Res. 1443, 1-17. doi: 10.1016/j.brainres.2012. 01.005

McCormick, C. M., and Mathews, I. Z. (2007). HPA function in adolescence: role of sex hormones in its regulation and the enduring consequences of exposure to stressors. Pharmacol. Biochem. Behav. 86, 220-233. doi: 10.1016/j.pbb.2006. 07.012

McCormick, C. M., Mathews, I. Z., Thomas, C., and Waters, P. (2010). Investigations of HPA function and the enduring consequences of stressors in adolescence in animal models. Brain Cogn. 72, 73-85. doi: 10.1016/j.bandc. 2009. 06.003

Musatov, S., Chen, W., Pfaff, D. W., Kaplitt, M. G., and Ogawa, S. (2006). RNAimediated silencing of estrogen receptor alpha in the ventromedial nucleus of hypothalamus abolishes female sexual behaviors. Proc. Natl. Acad. Sci. U S A 103, 10456-10460. doi: 10.1073/pnas.0603045103

Nelson, R. J. (2005). An Introduction to Behavioral Endocrinology. Sunderland: Sinauer Associates.

Ogawa, S., Eng, V., Taylor, J., Lubahn, D. B., Korach, K. S., and Pfaff, D. W. (1998). Roles of estrogen receptor-alpha gene expression in reproduction-related behaviors in female mice. Endocrinology 139, 5070-5081. doi: 10.1210/en.139. 12.5070

Ouchi, H., Ono, K., Murakami, Y., and Matsumoto, K. (2013). Social isolation induces deficit of latent learning performance in mice: a putative animal model of attention deficit/hyperactivity disorder. Behav. Brain Res. 238, 146-153. doi: 10.1016/j.bbr.2012.10.029

Park, J. H. (2011). “Assessment of male sexual behavior in mice," in Mood and Anxiety Related Phenotypes in Mice: Characterization Using Behavioral Tests, ed T. D. Gould (New York: Humana Press), 357-373.

Pietropaolo, S., Singer, P., Feldon, J., and Yee, B. K. (2008). The postweaning social isolation in C57BL/6 mice: preferential vulnerability in the male sex. Psychopharmacology (Berl) 197, 613-628. doi: 10.1007/s00213-0081081-3

Rissman, E. F., Wersinger, S. R., Fugger, H. N., and Foster, T. C. (1999). Sex with knockout models: behavioral studies of estrogen receptor alpha. Brain Res. 835, 80-90. doi: 10.1016/s0006-8993(99)01452-3
Ruscio, M. G., Sweeny, T. D., Gomez, A., Parker, K., and Carter, C. S. (2009). Social environment alters central distribution of estrogen receptor alpha in juvenile prairie voles. Physiol. Behav. 98, 296-301. doi: 10.1016/j.physbeh.2009.06.005

Sah, P., Faber, E. S., Lopez De Armentia, M., and Power, J. (2003). The amygdaloid complex: anatomy and physiology. Physiol. Rev. 83, 803-834. doi: 10.1152/ physrev.00002.2003

Schulz, K. M., Molenda-Figueira, H. A., and Sisk, C. L. (2009). Back to the future: the organizational-activational hypothesis adapted to puberty and adolescence. Horm. Behav. 55, 597-604. doi: 10.1016/j.yhbeh.2009.03.010

Schulz, K. M., and Sisk, C. L. (2006). Pubertal hormones, the adolescent brain and the maturation of social behaviors: lessons from the Syrian hamster. Mol. Cell. Endocrinol. 254-255, 120-126. doi: 10.1016/j.mce.2006.04.025

Simerly, R. B., and Young, B. J. (1991). Regulation of estrogen receptor messenger ribonucleic acid in rat hypothalamus by sex steroid hormones. Mol. Endocrinol. 5, 424-432. doi: 10.1210/mend-5-3-424

Sisk, C. L., and Zehr, J. L. (2005). Pubertal hormones organize the adolescent brain and behavior. Front. Neuroendocrinol. 26, 163-174. doi: 10.1016/j.yfrne.2005. 10.003

Spiteri, T., Musatov, S., Ogawa, S., Ribeiro, A., Pfaff, D. W., and Agmo, A. (2010a). Estrogen-induced sexual incentive motivation, proceptivity and receptivity depend on a functional estrogen receptor alpha in the ventromedial nucleus of the hypothalamus but not in the amygdala. Neuroendocrinology 91, 142-154. doi: $10.1159 / 000255766$

Spiteri, T., Musatov, S., Ogawa, S., Ribeiro, A., Pfaff, D. W., and Agmo, A. (2010b). The role of the estrogen receptor alpha in the medial amygdala and ventromedial nucleus of the hypothalamus in social recognition, anxiety and aggression. Behav. Brain Res. 210, 211-220. doi: 10.1016/j.bbr.2010.02.033

Takasugi, N., Tanaka, M., and Kato, H. (1983). Occurrence of lordosis-like posture in male and female mice given manual stimulation during the early period of anesthesia. Endocrinol. Jpn. 30, 29-33. doi: 10.1507/endocri1954.30.29

Wersinger, S. R., Haisenleder, D. J., Lubahn, D. B., and Rissman, E. F. (1999). Steroid feedback on gonadotropin release and pituitary gonadotropin subunit mRNA in mice lacking a functional estrogen receptor alpha. Endocrine 11, 137-143. doi: 10.1385/endo:11:2:137

Wersinger, S. R., Sannen, K., Villalba, C., Lubahn, D. B., Rissman, E. F., and De Vries, G. J. (1997). Masculine sexual behavior is disrupted in male and female mice lacking a functional estrogen receptor alpha gene. Horm. Behav. 32, 176183. doi: 10.1006/hbeh.1997.1419

Conflict of Interest Statement: The authors declare that the research was conducted in the absence of any commercial or financial relationships that could be construed as a potential conflict of interest.

Received: 16 June 2014; accepted: 08 September 2014; published online: 29 September 2014.

Citation: Kercmar J, Tobet SA and Majdic G (2014) Social isolation during puberty affects female sexual behavior in mice. Front. Behav. Neurosci. 8:337. doi: 10.3389/fnbeh.2014.00337

This article was submitted to the journal Frontiers in Behavioral Neuroscience.

Copyright $(\odot) 2014$ Kercmar, Tobet and Majdic. This is an open-access article distributed under the terms of the Creative Commons Attribution License (CC BY). The use, distribution and reproduction in other forums is permitted, provided the original author(s) or licensor are credited and that the original publication in this journal is cited, in accordance with accepted academic practice. No use, distribution or reproduction is permitted which does not comply with these terms. 